\title{
Evolution of acute chest syndrome in sickle cell trait: an ultrastructural and light microscopic study
}

\author{
P S HASLETON, K ORR, A WEBSTER, R A M LAWSON \\ From the Departments of Histopathology and Cardiothoracic Surgery, Regional Cardiothoracic Centre, \\ Wythenshawe Hospital, Manchester
}

\begin{abstract}
Light and electron microscopic studies of a patient with sickle cell trait who had an episode of sickling during coronary artery surgery, from which he died, showed fibrin thrombi, focal alveolar wall necrosis, and epithelial cell damage. It is suggested that in cases of sickle cell trait full precautionary measures should be taken to prevent sickling in these circumstances.
\end{abstract}

The changes seen in the lung at necropsy in patients with sickle cell disease are well documented, and include alveolar wall necrosis, emboli of necrotic bone marrow, and intravascular thrombosis. ${ }^{1-2}$ The morphological features of the acute chest syndrome, on the other hand, have not been investigated to the same extent. This condition is a complication of sickle cell disease characterised by fever, chest pain, and pulmonary infiltrates. ${ }^{34}$ Its exact pathogenesis is unknown, but it may be precipitated by pulmonary infection or infarction. It is unusual in patients with sickle cell trait. This paper reports the light and electron microscopic appearances of the lung in a patient with sickle cell trait who had an episode of sickling during coronary artery surgery.

\section{Case report}

A 54 year old normotensive black man, who smoked 20 cigarettes a day, presented with a six year history of postinfarction angina and reduced exercise tolerance. The sickledex test gave a positive response, and electrophoresis confirmed sickle cell trait. Vein grafts were inserted in the anterior descending and distal right coronary arteries during cardiac bypass. Lung biopsy specimens were taken before and after bypass as part of another investigation.

Forty eight hours later the patient developed adult respiratory distress syndrome, and the chest was re-explored to exclude cardiac tamponade. The right coronary artery graft had thrombosed, the pulmonary arterial pressure was raised, and the lungs were congested. The patient died the same day.

At necropsy the heart was enlarged, and there was recent infarction of the posterior wall of the left ventricle. Foci of marrow infarction were present in the lumbar vertebrae.

Address for reprint requests: Dr P S Hasleton, University of Manchester School of Medicine, Wythenshawe Hospital, Manchester M23 9LT.

Accepted 5 July 1989
Histologically, the lungs showed congestion, oedema, focal alveolar wall necrosis with early acute inflammation, hyaline membranes, and fibrin thrombi in some small arteries. In addition, there were foci of pulmonary infarction and areas of intra-alveolar haemorrhage containing some sickled cells. Occasional nucleated red cells were also present.

Light microscopy of the prebypass biopsy specimen showed alveolar emphysema, alveolar walls of normal thickness, and sickling of red cells. Electron microscopy showed intravascular vesicles and some sickled red cells (fig 1). Micropinocytic vesicles in endothelial cells were slightly enlarged, and there was focal cytoplasmic lucency. The basement membrane was thickened and contained vesicles, and there were mast cells in the interstitium. Type II pneumocytes were normal; but type I pneumocytes were enlarged with surface papillary projections, and mitochondria were swollen. In some cells the cytoplasm was lucent, and intercellular junctions were wide. Some alveolar lining cells were lost, leaving a denuded basement membrane.

In the specimen taken after bypass the sickling was more noticeable, intravascular fibrin thrombus was present, and there was some interstitial oedema. No hyaline membranes or megakaryocytes were identified. Ultrastructurally, there were abnormal red cells in many vessels, and more endothelial cell degeneration than in the first biopsy specimen. Intracapillary vesicles were more abundant, and there was more interstitial and basement membrane thickening (fig 2) and ingrowth of mast cells and fibroblasts. Degenerative change in type I cells was now severe, and there were similar changes in the scanty type II cells. The basement membrane was denuded over wide areas.

\section{Discussion}

There is no doubt that our patient had an episode of sickling during surgery and immediately afterwards. Sickle cell trait with a haemoglobin $S$ carrier rate of up to $17.6 \%$ is found in children of African descent in Great Britain, ${ }^{5}$ and hypoxia may induce sickling in these patients. In the present case sickled cells were identified histologically in the biopsy specimens taken before and after bypass and in the necropsy material. In addition, the necropsy material showed alveolar wall necrosis and focal pulmonary infarction, both of which are characteristic of the lung lesions in sickle cell disease. Although neither the adult respiratory distress syndrome nor the acute chest syndrome have been described in sickle cell trait, the changes in the lung can reasonably be attributed to the blood disorder. Moreover, the damage to the lung parenchyma caused by sickling at operation is likely to have 


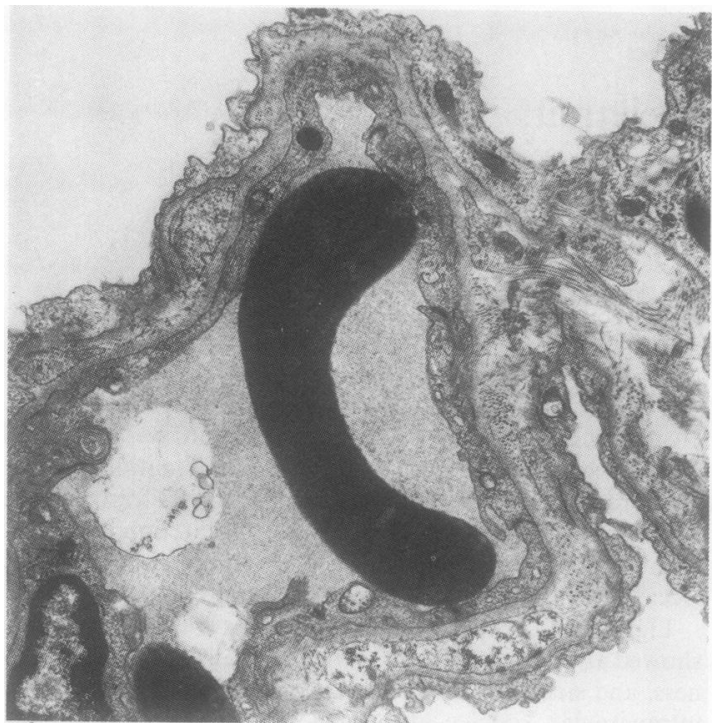

Fig 1 Lung biopsy material taken before bypass showing a sickled red cell but a normal alveolar wall. (Uranyl acetate and lead citrate.)

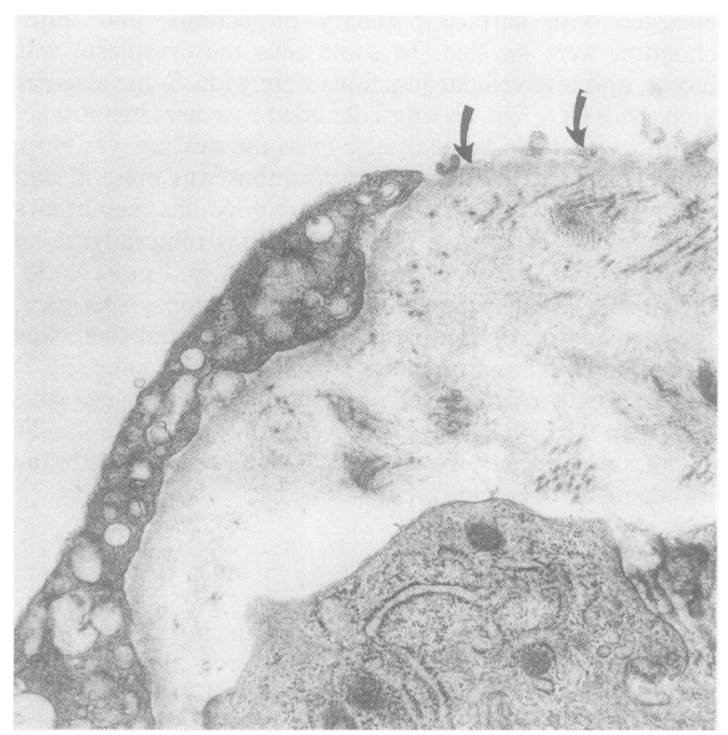

Fig 2 Lung biopsy material taken after bypass showing considerable thickening of the basement membrane and focal loss (arrows) of type I cell cytoplasm. (Uranyl acetate and lead citrate.)

been a major factor in the pathogenesis of the adult respiratory distress syndrome.

The light and electron microscopic appearances in the operative biopsy specimens were similar to those we have found in a study (not yet published) of haematologically $\overrightarrow{\vec{F}}$ normal patients undergoing cardiopulmonary bypass, $\overrightarrow{0}$ though the changes were more severe, with fibrin thrombi, $\frac{\mathrm{C}}{2}$ focal alveolar wall necrosis, and degeneration of lining cells. Endothelial cell damage was surprisingly inconspicuous $\frac{\tilde{\sigma}}{\overparen{\sigma}}$ despite intravascular sickling and thrombosis. Changes in the endothelial cells were also minimal in the other patients, ® many of whom were considered to be in the early stages of adult respiratory distress syndrome. It has been widely. accepted that damage to the pulmonary endothelial cell is $\vec{\overrightarrow{ }}$ central to the pathogenesis of adult respiratory distress $\vec{\sigma}$ syndrome. ${ }^{6}$ Our investigations, including the studies on this $\vec{F}$ case, suggest that the brunt of the damage is borne by the $x$ epithelial cells in this latter condition as well as in the acute $\vec{f}$ chest syndrome.

In a Jamaican study of open heart surgery in patients with $\vec{N}$ sickle cell trait and sickle cell disease there were no deaths $\vec{\circ}$ from sickling, and there was little difference in operative $y$ mortality between heterozygous and homozygous patients. ${ }^{\prime}$ 을 In patients with more than $30 \% \mathrm{HbS}$ a transfusion of 250 $500 \mathrm{ml}$ of blood was given before bypass to minimise the risk $\square$ of sickling. Other authorities ${ }^{89}$ have recommended that in $\mathbb{D}$ such patients particular care should be taken to avoid $\Phi$ acidosis and to maintain normal $\mathrm{PaO}_{2}$. The $\mathrm{HbS}$ concentra- $\frac{3}{0}$ tions should be reduced to less than $30 \%$ by preoperative $\stackrel{\mathbb{Q}}{-}$ exchange transfusion. The only precaution taken in our case $\vec{\bullet}$ was to avoid excessive cooling, but our experience suggests $\varnothing$ that full precautionary measures should be taken in patiends with sickle cell trait as well as in those with sickle cell diseas

We acknowledge W O Street Charitable Trust, ICI, Ledef Laboratories, the Radivan Trust and Ainsworth Benevolent Fund for their help in this study.

\section{References}

1 Haupt HM, Moove GW, Bauer TW. Hutchins GM. The lung in sickle cell disease. Chest 1982;81:332-7.

2 Anonymous. Case Records of the Massachusetts General Hospital. $N$ Engl J Med 1983;309:1627-36.

3 Davies SC, Luce PJ, Win AA, Riordan JF, Brozovic M. Acute chest syndrome in sickle cell disease. Lancet 1984;i:36-8.

$4 \mathrm{Knasel} A$. Is sickle cell trait a health hazard? Medical problems: a brief review. Am J Pediatr Haematol Oncol 1982;4:179-81.

5 Murtaza LN, Stroud CE, Davis LR, Cooper DJ. Admissions to hospital of children with sickle cell anaemia: a study in South London. Br Med J 1981;282:1048-51.

6 Rinaldo JE, Rogers RM. Adult respiratory distress syndrome: changing concepts of lung injury and repair. $N$ Engl $J$ Med 1982;306:900-9.

7 Sivapragasam S, Shah S, Chatoorgoon A. Open heart surgery in patients with sickle haemoglobin 1968-1978. West Indian Med $J$ 1980;29 (suppl):336-41.

8 Yacoub MA, Baron J, Adel El-Etr, Kittle CF. Aortic homograft replacement of the mitral valve in sickle cell trait. $J$ Thorac Cardiovasc Surg 1970:59:568-73.

9 Ingram CT, Floyd JB. Santora AA. Aortic and mitral valve replacement after sickle cell disease. Anaesth and Analg 1982;61:802. 